\title{
Ultraselective conventional transarterial chemoembolization: When and how?
}

\author{
Shiro Miyayama \\ Department of Diagnostic Radiology, Fukui-ken Saiseikai Hospital, Fukui, Japan
}

Ultraselective conventional transarterial chemoembolization (CTACE), defined as CTACE at the most distal portion of the subsubsegmental hepatic artery, is mainly performed for hepatocellular carcinoma (HCC) $\leq 5 \mathrm{~cm}$. Distal advancement of a microcatheter enables injection of a larger volume of iodized oil into the portal vein in the limited area under non-physiological hemodynamics. As a result, the reversed portal flow into the tumor through the drainage route of the tumor that occurs when the hepatic artery is embolized is temporarily blocked. By adding gelatin sponge slurry embolization, both the hepatic artery and portal vein are embolized and not only complete necrosis of the tumor but also massive peritumoral necrosis can be achieved. Ultraselective cTACE can cure small HCCs including less hypervascular tumor portions and replace surgical resection and radiofrequency ablation in selected patients. (Clin Mol Hepatol 2019;25:344-353)

Keywords: Chemoembolization, Therapeutic; Hepatocellular carcinoma; lodized oil; Gelatin sponge, Absorbable; Conebeam computed tomography

\section{INTRODUCTION}

Transarterial chemoembolization (TACE) is the most commonly performed therapy for inoperable hepatocellular carcinoma (HCC), although the necessity of chemotherapeutics is still controversial. ${ }^{1,2}$ Now, two major techniques are performed: TACE using iodized oil (Lipiodol 480; Guerbet Japan, Tokyo, Japan) emulsion and gelatin sponge (GS) particles (conventional TACE; CTACE); and TACE using drug-eluting beads. The former technique has been mainly developed in Asian countries, and it is a standard treatment option for localized HCCs. However, the therapeutic effects of CTACE are strongly influenced by technical aspects. ${ }^{3-5}$ Ultraselective CTACE is defined as CTACE at the most distal portion of the tumor-feeding subsubsegmental hepatic artery and has a strong therapeutic effect on $\mathrm{HCCs}{ }^{5-8}$ Therefore, it is important to understand the rationale and techniques of ultraselective CTACE.

\section{WHY IS ULTRASELECTIVE CTACE NECESSARY?}

Complete response at the first TACE is the most robust predictor of a favorable outcome. ${ }^{9}$ It is well-known that TACE loads hypoxic and chemotherapeutic stress on HCC and the surviving tumors frequently change to sarcomatous ${ }^{10}$ or mixed hepatocholangiocelIular" phenotypes, which are usually more aggressive and TACEresistant. Hypoxia induced by TACE also stimulates vascular endo-

\footnotetext{
Abbreviations:

AFD, automated tumor-feeder detection; BCLC, Barcelona Clinic Liver Cancer; $C B C T$, cone-beam computed tomography; $C T$, computed tomography; $C T A C E$, conventional transarterial chemoembolization; DSA, digital subtraction angiography; GS, gelatin sponge; HCC, hepatocellular carcinoma; TAA, transarterial ablation; TACE, transarterial chemoembolization; VEGF, vascular endothelial growth factor
}

\section{Corresponding author : Shiro Miyayama}

Department of Diagnostic Radiology, Fukui-ken Saiseikai Hospital, 7-1 Funabashi, Wadanaka-cho, Fukui 918-8503, Japan

Tel: +81-776-23-1111, Fax: +81-776-28-8519

E-mail: s-miyayama@fukui.saiseikai.or.jp

https://orcid.org/0000-0001-6119-5874 
thelial growth factor (VEGF) production by the residual tumor cells. ${ }^{12}$ Intrahepatic distant recurrence also develops more frequently in patients with local tumor progression after CTACE than in patients without local tumor progression. ${ }^{13}$ This indicates that some intrahepatic distant recurrence may be related to local tumor progression: metastases from locally progressed tumors or newly developed tumors promoted mainly by high expression of VEGF production from the residual tumor cells. Furthermore, some surviving tumors are fed by collateral vessels, ${ }^{14,15}$ and infrequently by the portal vein if the arterial branches including extrahepatic collateral arteries are severely damaged. ${ }^{16,17}$ These suggest that TACE is also associated with the risk of causing uncontrollable tumors. Therefore, "curative TACE" is necessary to obtain favorable outcomes.

TACE damages not only the liver parenchyma but also the hepatic artery by arteritis, and attenuation of the hepatic artery reduces the hepatic function ${ }^{18}$ and exaggerates the development of extrahepatic collaterals. ${ }^{14,15}$ To prolong the duration of transcatheter management, damage to the hepatic artery by TACE should be minimized. In addition, selective catheterization can reduce the total dose of iodized oil and minimize liver toxicity. Therefore, ultraselective cTACE is a skill that overcomes the negative effects of TACE.

\section{RATIONALE FOR ULTRASELECTIVE cTACE}

Moderately to poorly differentiated HCC tissue is predominantly supplied by arterial blood. ${ }^{19}$ However, some tumor portions, such as capsular and/or extracapsular tumor invasions, microsatellite lesions, and well differentiated tumor portions, are usually supplied by both the hepatic artery and portal vein. ${ }^{3}$ Additionally, portal blood flows into the tumor via the drainage route from HCC when hepatic arterial flow is blocked, ${ }^{20}$ and this may help tumor survival after TACE. ${ }^{16,17}$ Moreover, some arterial blood can also supply the tumor through intra- and/or extrahepatic microarterial communications. ${ }^{21,22}$ As a result, tumor tissues supplied by collateral flows including portal blood, in addition to the tumor portions originally supplied by both arterial and portal blood, may survive mainly at the periphery of $\mathrm{HCC}$ when the arterial side is simply blocked with a particulate embolus. ${ }^{7,8}$

lodized oil is a semi-fluid embolic agent that can embolize the capillary vessels and enhance the ischemic effects of TACE. Iodized oil injected into the hepatic artery is first retained in the tumor sinusoids. When pooling iodized oil has exceeded a certain volume in the tumor sinusoids, some flows into the portal veins through the peribiliary plexus and drainage route from HCC. ${ }^{5,23}$ The overflowing iodized oil can temporarily block reversed portal flow toward the tumor. In addition to the inflow of iodized oil in the portal vein, some also flows into the neighboring hepatic arterial branches, and sometimes into the extrahepatic arteries, ${ }^{22,24}$ mainly through the isolated artery and capsular arterial plexus of the liver. ${ }^{22}$ This allows embolization or identification of "an occult tumor-feeder". However, the embolic effect of iodized oil emulsion is temporary; therefore, arterial blockage with a particulate embolus is necessary. By adding GS particle embolization, both the hepatic artery and portal vein are embolized and not only complete necrosis of the tumor but also massive peritumoral necrosis can be achieved. ${ }^{4-8}$

It is well-known that the catheter position during CTACE strongly influences the local therapeutic effects and outcomes. ${ }^{3-5}$ In ultraselective CTACE, embolic agents distally flow away due to not only physiological blood flow but also the injection force generated by blockage of the backflow of embolic agents by a catheter's mass effect and stretching of the catheterized tumor-feeder (Fig. 1). This condition enables active injection of embolic agents and the dose of iodized oil reaching the portal veins increases.$^{5-8}$ In other words, ultraselective CTACE enables injection of a larger volume of embolic agents into the limited area under non-physiological hemodynamics. Therefore, the effect of ultraselective CTACE is not as markedly influenced by the tumor morphology or vascularity (Fig. 2, 3). ${ }^{7.8,25}$

\section{INDICATION OF ULTRASELECTIVE TACE}

According to the Barcelona Clinic Liver Cancer (BCLC) staging system, TACE is recommended for intermediate-stage (stage B) HCC patients. ${ }^{26}$ However, this stage includes various tumor conditions and there is no consensus on which tumors are indicated for superselective TACE. TACE techniques impact on patient survival, and selective/superselective CTACE could achieve a significantly better prognosis compared with non-selective CTACE in patients with $\mathrm{HCC} \leq 7 \mathrm{~cm}$ and $\leq 5$ lesions. ${ }^{27}$ Among BCLC-B HCC patients treated with CTACE, better overall survival was achieved in a patient subgroup with Child-Pugh A class and tumors $\leq 7 \mathrm{~cm}$ and $\leq 4$ lesions. ${ }^{28}$ The Child-Pugh score was also a significant prognostic factor, and the prognosis of Child-Pugh score 9 patients after CTACE was poorer than that of the best supportive care group in a previous randomized controlled trial. ${ }^{29,30}$ These suggest that pa- 


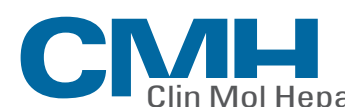

Volume 25 Number 4 December 2019
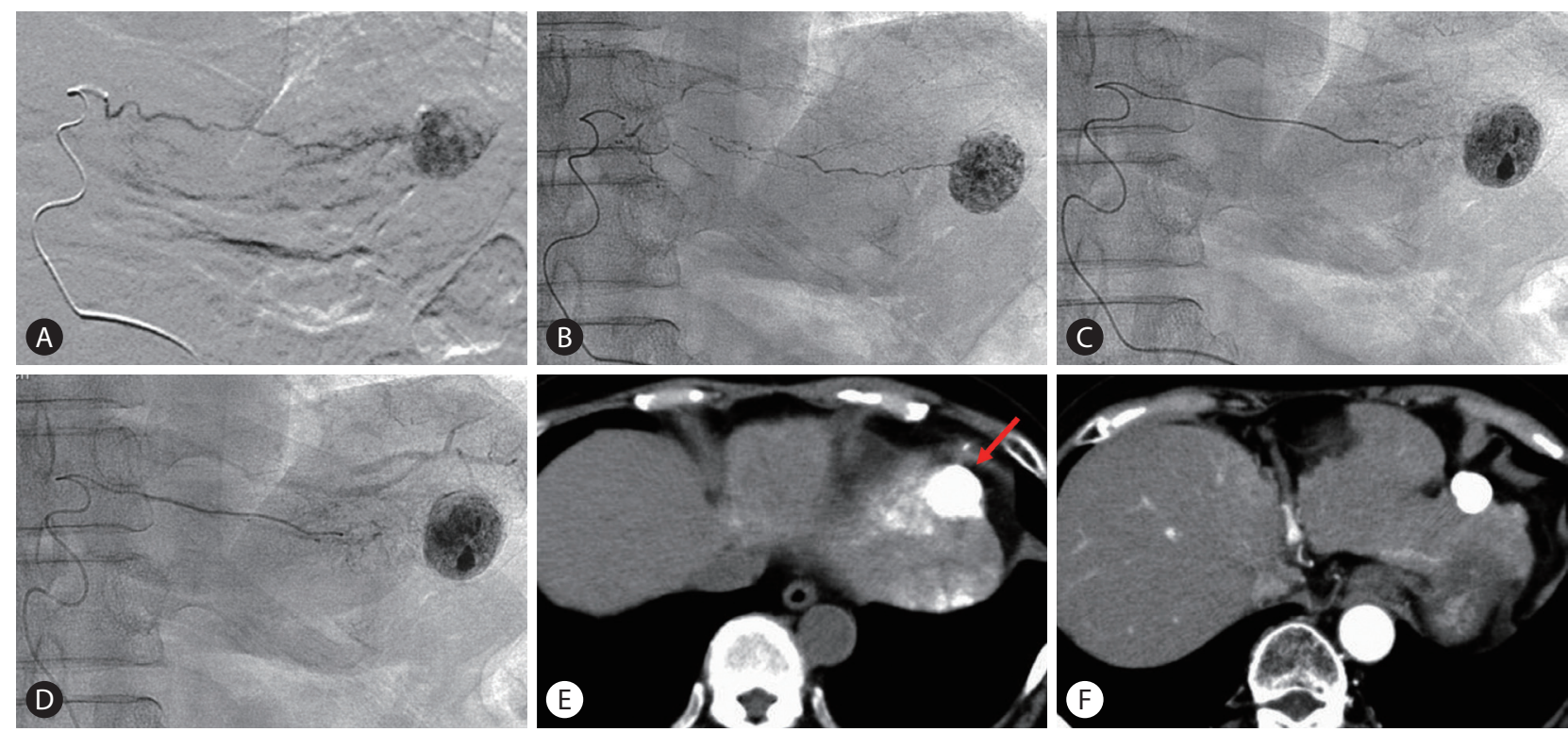

Figure 1. Ultraselective conventional transarterial chemoembolization (CTACE) for small hepatocellular carcinoma. (A) Arteriogram of a branch of A3 showed tumor stain supplied by the tortuous tumor-feeder. (B) First, iodized oil emulsion was injected into the proximal portion of the tumor-feeder, but the arterial flow was stopped before sufficient portal vein visualization with iodized oil. (C) So, the injection was stopped and the microcatheter was advanced more distally. Thereafter, iodized oil emulsion was re-injected. (D) During ultraselective cTACE, portal veins were markedly opacified with iodized oil. (E) Unenhanced computed tomography (CT) performed 1 week after ultraselective cTACE showed dense iodized oil accumulation in the tumor (arrow). (F) Arterial phase CT performed 2 years and 6 months after ultraselective CTACE showed no tumor recurrence.
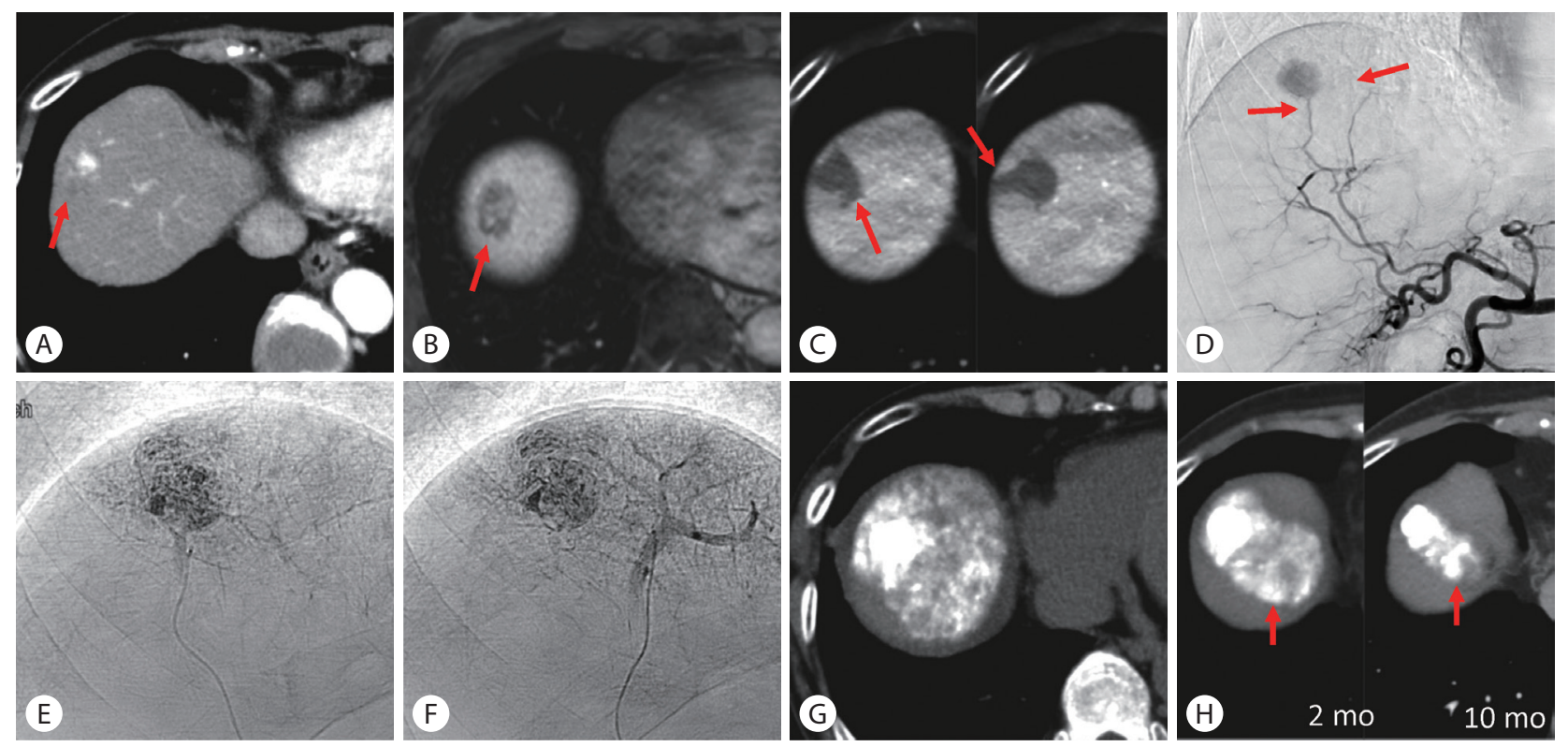

Figure 2. Ultraselective conventional transarterial chemoembolization (CTACE) for hepatocellular carcinoma (HCC) with extracapsular and microvascular invasion. (A) Arterial phase computed tomography (CT) showed a hypervascular HCC with hypovascular extracapsular invasion (arrow) in segment 8. (B) Hepatobiliary-phase of gadoxetate disodium-enhanced magnetic resonance imaging also showed extracapsular invasion (arrow). (C) Cone-beam CT (CBCT) during arterial portography showed microvascular invasion around the tumor (arrows). (D) Celiac arteriogram showed tumor stain supplied by two feeders (arrows). (E, F) Each feeder was selectively embolized using a 1.5-F tip microcatheter and portal veins were markedly opacified during ultraselective cTACE. (G) Unenhanced CT performed 1 week after ultraselective cTACE showed dense iodized oil accumulation in the entire tumor including the hypovascular tumor portion. (H) Serial CT images showed that the tumor has remained well controlled 10 months after ultraselective CTACE. lodized oil was also retained in the normal liver parenchyma (arrows), indicating hepatic necrosis. mo, months. 

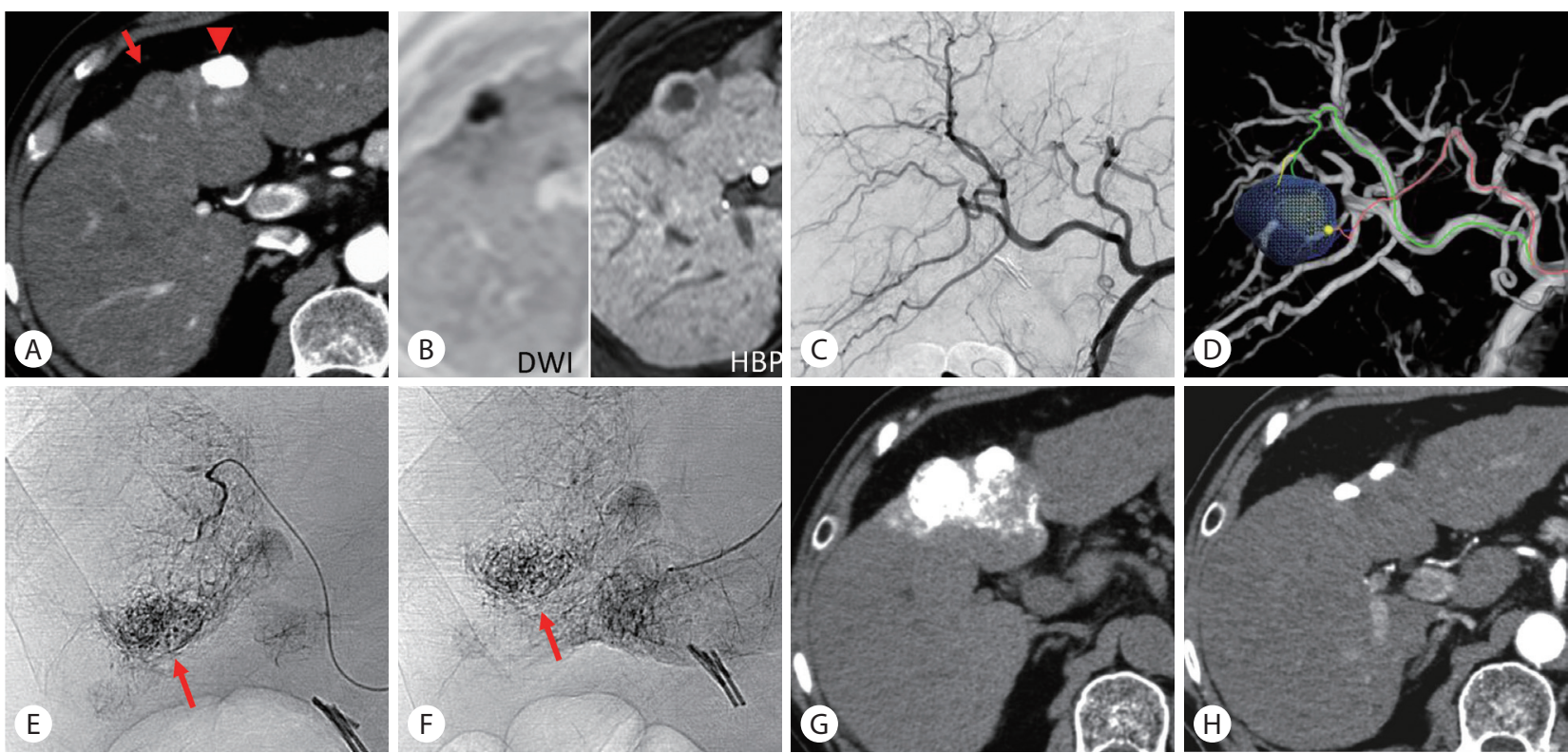

Figure 3. Ultraselective conventional transarterial chemoembolization (CTACE) for hypovascular hepatocellular carcinoma. (A) Arterial phase computed tomography (CT) showed a hypovascular tumor in segment 4 (arrow) near the previously embolized tumor (arrowhead). (B) The tumor showed hyperintensity on diffusion-weighted magnetic resonance imaging (MRI) and hypointensity with a hyperintense rim on hepatobiliary-phase of gadoxetate disodium-enhanced MRI. (C) Common hepatic arteriogram showed no tumor staining. (D) TACE guidance software identified two tumor-feeders. (E, F) Each branch was selectively embolized using a 1.5-F tip microcatheter. The arrows indicate the tumor. (G) Unenhanced CT performed 1 week after ultraselective CTACE showed iodized oil accumulation in the entire tumor. $(\mathrm{H})$ Arterial phase CT performed 1 year and 2 months after ultraselective cTACE showed complete tumor necrosis. DWI, diffusion-weighted image; HBP, hepatobiliary-phase.

tients with Child-Pugh score $\leq 8$ and HCC $\leq 7 \mathrm{~cm}$ and $\leq 4-5$ lesions are good candidates for ultraselective CTACE. On considering the limitation of the dose of iodized oil $(\leq 10 \mathrm{~mL}$ in a single session $^{31,32}$ ) and the size of embolized areas, ultraselective CTACE is mainly performed for tumors $\leq 5 \mathrm{~cm}$. In addition, ultraselective CTACE is an alternative treatment for selected BCLC 0-A HCC patients because it can achieve complete necrosis of some less hypervascular tumors by the active injection of embolic agents into a tiny tumor-feeder (Fig. 3). ${ }^{25}$

\section{TECHNIQUES OF ULTRASELECTIVE cTACE}

The embolic effect of iodized oil emulsion can be changed by preparation techniques. The yield stress values of water-in-oil emulsion are more than 47 times higher than those of oil-in-water emulsion. ${ }^{33}$ Therefore, water-in-oil emulsion has a stronger embolic effect than oil-in-water emulsion and pure iodized oil. ${ }^{34}$ In addition, adding arterial blockage with GS particles can increase the intratumoral concentration of chemotherapeutics and decrease the blood levels. ${ }^{35} \mathrm{~A}$ recent report showed that the mean diameter of tumor-feeders supplying tumors 7-63 mm (mean \pm standard deviation [SD], $20.3 \pm 12.7 \mathrm{~mm}$ ) in diameter was $0.12-1.79 \mathrm{~mm}$ (mean $\pm S D, 0.41 \pm 0.32 \mathrm{~mm}$ ). ${ }^{36}$ Therefore, GS slurry approximately $0.2 \mathrm{~mm}$ in diameter crushed by a pumping method is mainly used in ultraselective CTACE $^{5-8,25}$ because only 1- and 2-mm GS particles (Gelpart; Nippon Kayaku, Tokyo, Japan) are commercially available in Japan.

After the advancement of a microcatheter in the tumor-feeder, $0.5 \mathrm{~mL}$ of $2 \%$ lidocaine (Terumo, Tokyo, Japan) is injected through the microcatheter to prevent pain and vasospasm. ${ }^{5-8}$ Then, iodized oil emulsion dissolved with 1-2 chemotherapeutics (doxorubicin [Adriacin; Aspen Japan, Tokyo, Japan], epirubicin [Farmorbicin; Pfizer, Tokyo, Japan], cisplatin [IA-call; Nippon Kayaku], mitomycin C [Mitomycin; Kyowa Hakko Kirin, Tokyo, Japan], or miriplatin [Miripla; Dainippon Sumitomo, Osaka, Japan]) is slowly injected, followed by GS slurry. Although there are no standard techniques for preparing iodized oil emulsion, we usually mix 2-10 mL of iodized oil with contrast medium one-third the quantity of iodized oil that dissolves $10-30 \mathrm{mg}$ of epirubicin and 2-6 mg of mitomycin $\mathrm{C}$ by a pumping method. 'The endpoint of iodized oil injection is portal vein visualization adjacent to the tumor (grade 1), ${ }^{5}$ not marked portal vein visualization in the whole embolized area (grade 2 ), ${ }^{5}$ because iodized oil in the tumor and embolized area is 
pushed into the portal vein by GS slurry injection and widely distributes into the whole embolized area, frequently beyond the embolized area. As a result, grade 2 visualization can be achieved (Fig. 4). ${ }^{8}$ Before the start of GS slurry injection, iodized oil in the arteries should be flushed by saline from the arterial lumen. The endpoint of GS slurry injection is complete occlusion of the tumorfeeder. If the volume of GS slurry in the microcatheter lumen is excessive and easily overflows, it can be aspirated using a $2.5-\mathrm{mL}$ syringe.

\section{TECHNICAL TIPS FOR EFFECTIVE ULTRASE- LECTIVE CTACE}

\section{Selection of a microcatheter}

The smaller-sized microcatheter facilitates selective catheterization into the tiny tumor-feeder and more distal advancement into the tortuous tumor-feeder. In addition, an angled-tip microcatheter can easily traverse the kinked vessel portion along a microwire compared with a straight-tip microcatheter. Now, we use a 1.5-F tip microcatheter with an angled-tip (Asahi Veloute Ultra; Asahi Intecc, Nagoya, Japan) in most ultraselective cTACE procedures (Fig. 2, 3). In addition, using steam to bend the microcatheter tip into J-shape is also useful for selective catheterization into a small vessel arising at an acute angle. ${ }^{37}$

\section{The order of embolization of each tumor-feeder}

In tumors with multiple feeders, the order of embolization of each feeder is key to performing effective CTACE. The main tumorfeeder should be embolized last because dense retention of iodized oil and contrast material obscures the residual tumor stain and other small feeders on digital subtraction angiography (DSA) performed immediately after ultraselective cTACE. In addition, embolic agents injected into the main tumor-feeder are sometimes pushed back by the reversed flow via the minor tumor-feeder. ${ }^{8}$ If the tumor is partially supplied by an extrahepatic artery, the feeding branch from the extrahepatic artery should be embolized first, if possible, because blood supply to tumors from the extrahepatic artery immediately increases when hepatic arterial flow is blocked. $^{38}$

The distal tumor-feeder should also be embolized first, and the proximal tumor-feeder should be embolized last to avoid inadvertently occluding the distal tumor-feeders with overflowing embolic agents (Fig. 5). ${ }^{8}$ However, feeders that are considered difficult to catheterize, such as the caudate artery or tiny tumor-feeders arising from extrahepatic arteries, should be embolized first, because the performance of a microcatheter-microwire system is usually best at the beginning of the procedure.

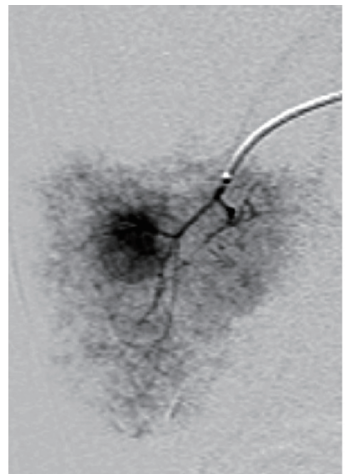

Grade 0

No obvious visualization

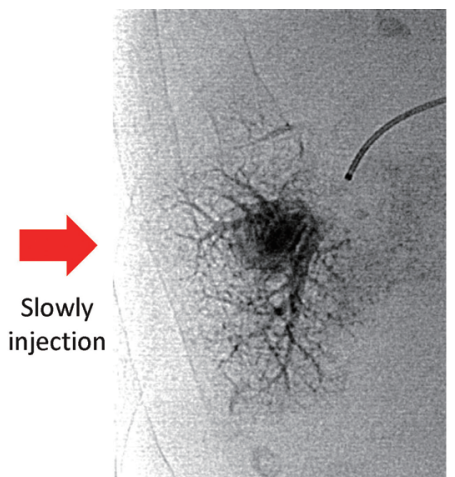

Grade 1

Visualization adjacent to tumor

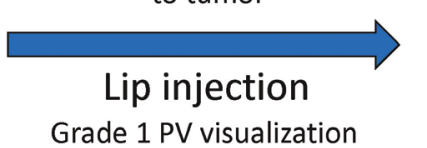

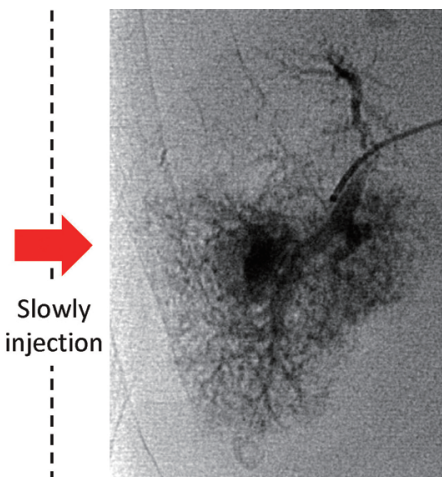

Grade 2

Visualization in the whole or extended embolized area

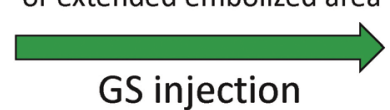

Occlusion of tumor-feeder

Figure 4. lodized oil emulsion should be slowly injected to avoid "oil cast formation" in the arteries. The endpoint of iodized oil emulsion injection is grade 1, not grade 2, because because iodized oil in the tumor and embolized area is pushed into the portal vein (PV) by gelatin sponge (GS) slurry injection and widely distributes into the whole embolized area, frequently beyond the embolized area. As a result, grade 2 visualization can be achieved. The endpoint of GS slurry injection is complete occlusion of the tumor-feeder. Modified from Miyayama and Matsui. ${ }^{7}$ 


\section{Technique to inject iodized oil emulsion}

lodized oil emulsion should be slowly injected to avoid "oil cast formation" in the arteries. When the flow of the tumor-feeder is unexpectedly stopped before sufficient portal vein visualization, two attempts should be made: injection of $0.5 \mu \mathrm{g}$ of prostaglandin E1 (Liple; Mitsubishi Tanabe Pharma, Osaka, Japan) or $0.5 \mathrm{~mL}$ of $2 \%$ lidocaine (Terumo) through the microcatheter to increase arterial flow; and distal advancement of the microcatheter to achieve a "semi-wedged condition" (Fig. 1). 5,7,8 The latter technique is recommended, if possible, because it is usually more effective. When the microcatheter is advanced more distally, injection of iodized oil emulsion can be re-started.

\section{Security of the safety margin for treatment}

HCC cells form intrahepatic satellite lesions, ${ }^{39}$ which are usually non-selective TACE-resistant because of dual arterial and portal blood supply. ${ }^{3}$ Most microsatellite lesions exist in the drainage area of tumor blood that is demonstrated as the corona area on computed tomography (CT) during hepatic arteriography. ${ }^{40,41}$ The corona area is a high-risk area of intrahepatic metastasis and should be included in the treatment area because tumor cells first spread there before entering the systemic circulation. ${ }^{41}$ Ultraselective CTACE can simultaneously treat the drainage area in most tumors because iodized oil flows into the corona area through the tumor drainage, and the corona area is usually included in the vascular territory of the tumor-feeder. ${ }^{7}$ In some cases, however, the drainage area is supplied by another arterial branch and subsequent selective embolization of this branch is required. Confirmation of the embolized areas using CT or cone-beam CT (CBCT) is useful for determining the endpoint. A safety margin at least $5 \mathrm{~mm}$ wide for HCC $<25 \mathrm{~mm}$ and $10 \mathrm{~mm}$ wide for HCC $\geq 25 \mathrm{~mm}$ should be achieved for each tumor, ${ }^{42}$ although the width of the corona is not actually uniform and is thick in places according to the tumor hemodynamics. $^{40,41}$
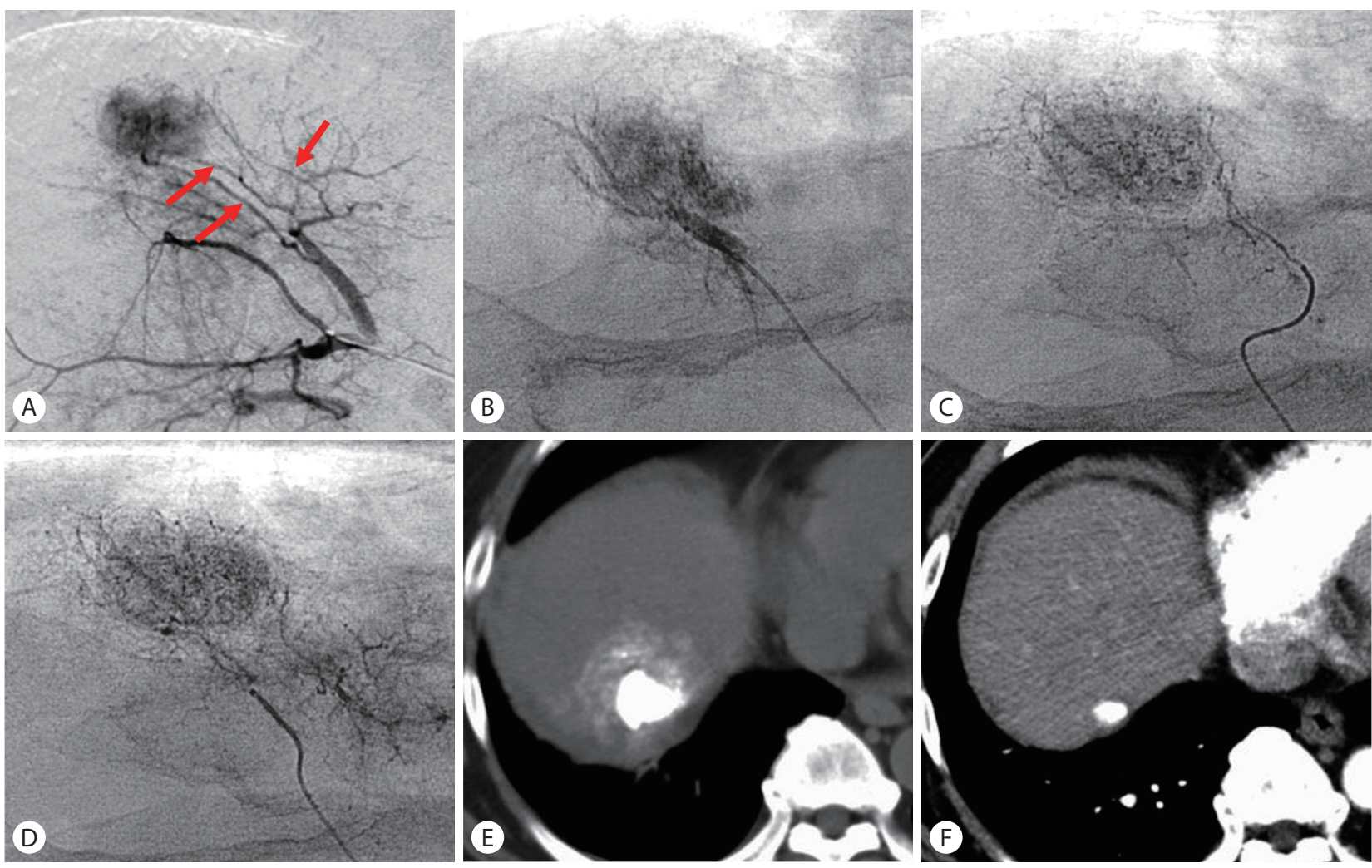

Figure 5. The order of embolization of each feeder. (A) Arteriogram of the anterior segmental artery of the right hepatic artery showed a tumor supplied by three tumor-feeders (arrows). (B-D) Each tumor-feeder was selectively embolized from distal to proximal to avoid inadvertently occluding the distal tumor-feeders with overflowing embolic agents. (E) Unenhanced computed tomography (CT) performed 1 week after ultraselective conventional transarterial chemoembolization (CTACE) showed dense iodized oil accumulation in the tumor. (F) Arterial phase CT performed 10 years and 4 months after ultraselective cTACE showed that the tumor has remained well controlled. 


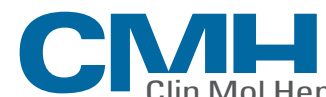

Clin Mol Hepatol

Volume 25 Number 4 December 2019

\section{CBCT and TACE guidance software}

CBCT is a new technology to obtain CT images during the TACE procedure. ${ }^{43}$ It has been reported that $\mathrm{CBCT}$ can improve not only local tumor control but also the prognosis of HCC patients. ${ }^{42,44}$ TACE guidance software, including automated tumor-feeder detection (AFD), is also a novel software using CBCT during hepatic arteriography data that can reduce the physician's workload and improve the treatment accuracy. ${ }^{45,46}$ Now, we routinely use TACE guidance software (EmboGuide; Philips Healthcare, Best, the Netherlands), and AFD analysis for up to 10 tumors can be completed within approximately 2 minutes (Fig. 3, 6). When the branch identified by AFD is agreed on a tumor-feeder, we embolize it without performing selective DSA. ${ }^{13}$ This can reduce the pro-
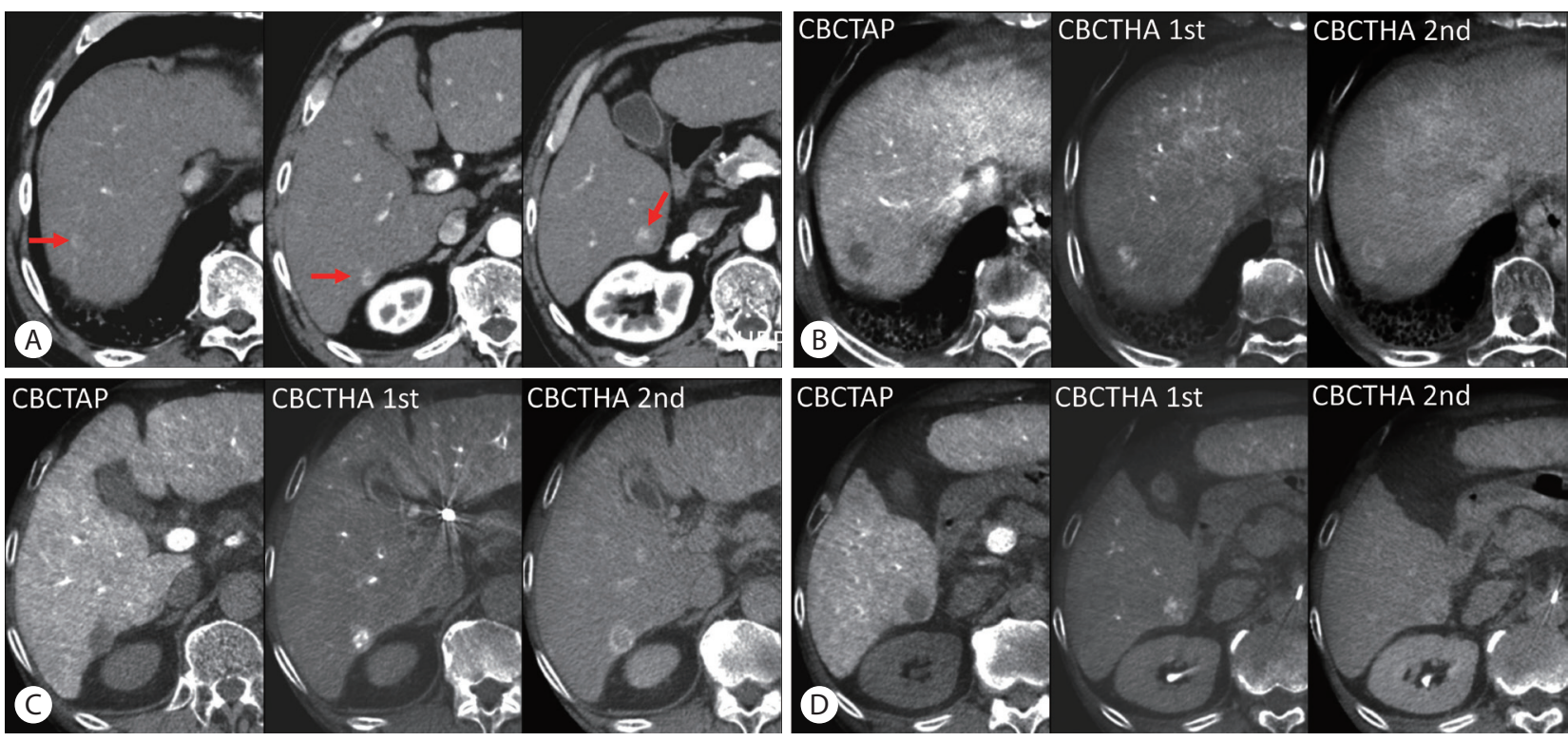

CBCTHA 1st

\section{CBCTHA 2nd}
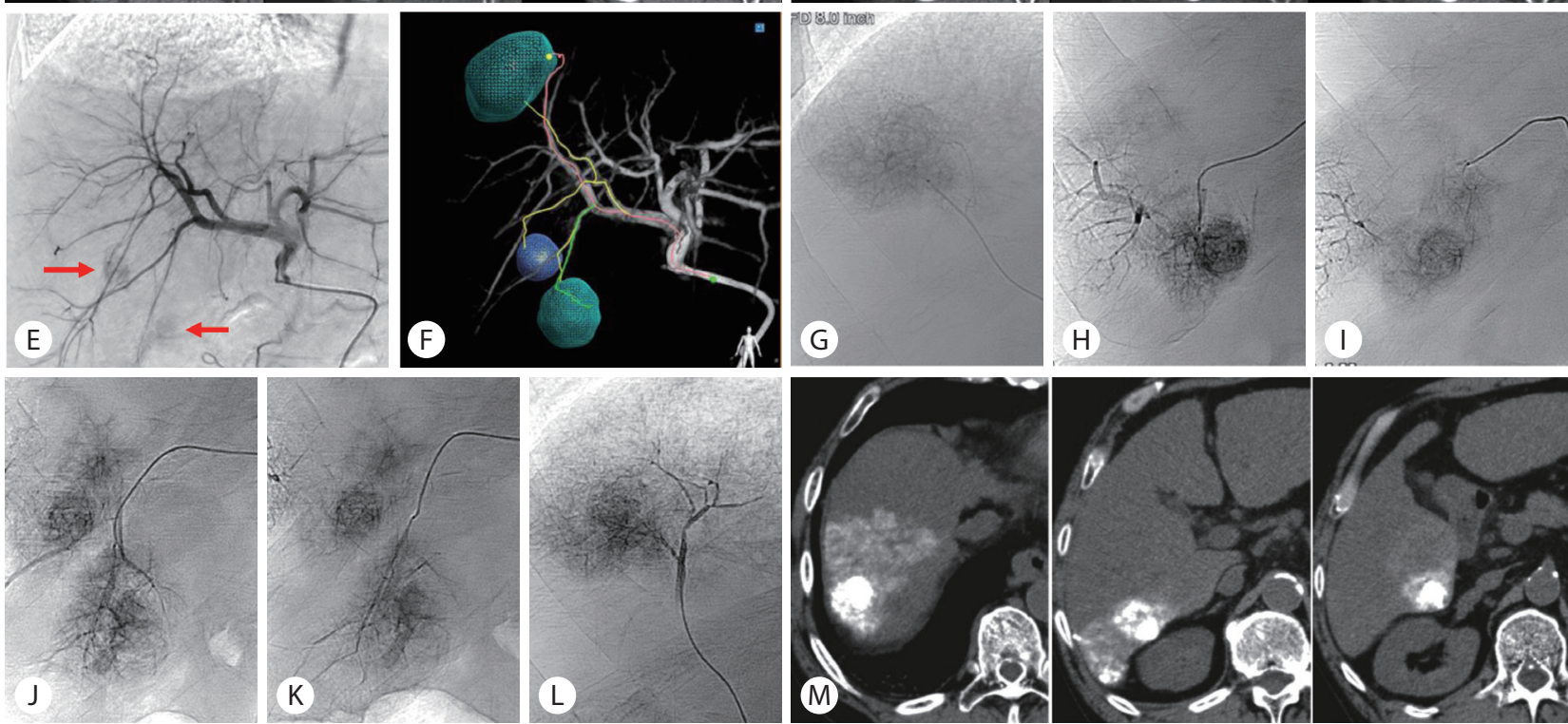

Figure 6. Cone-beam computed tomography (CBCT) and transarterial chemoembolization (TACE) guidance software. (A) Arterial phase computed tomography (CT) showed 3 small hepatocellular carcinomas in the right hepatic lobe (arrows). (B-D) CBCT during arterial portography (CBCTAP) and dual-phase CBCT during hepatic arteriography (CBCTHA) could depict all tumors. (E) Common hepatic arteriogram showed two faint tumor stains (arrows). However, the tumor-feeders were unclear. (F) TACE guidance software identified the feeders of each tumor. (G-L) Each tumor-feeder was selectively embolized. One branch (Fig. 6l) was not detected by TACE guidance software, but it was embolized on our decision. (M) Unenhanced CT performed 1 week after ultraselective conventional TACE showed dense iodized oil accumulation in all tumors with a sufficient safety margin. 
cedural time and doses of radiation exposure and contrast material. Based on our recent data, approximately $82 \%$ of tumors can be completely embolized with an adequate safety margin without confirmation by DSA and/or CBCT. ${ }^{13}$ Another advantage of TACE guidance software is that curability and invasiveness can be controlled according to the patient-tumor condition by adjusting the target size. ${ }^{13,46}$ The 5 -year survival rate of 102 patients with 190 $\mathrm{HCCs} \leq 7 \mathrm{~cm}$ and $\leq 5$ lesions (mean \pm SD maximum tumor diameter, $25.3 \pm 12.3 \mathrm{~mm}$ and mean $\pm \mathrm{SD}$ tumor number, $1.9 \pm 1.1$ lesions) was $60 \% .^{13}$ This indicates that TACE guidance software can improve the therapeutic effects of ultraselective cTACE. Now, we use protype virtual parenchymal perfusion software visualizing embolized areas according to the catheter position. ${ }^{47}$ In our retrospective analysis, the virtual embolization areas and real embolization areas were well correlated. It is expected that this software can improve the accuracy of ultraselective CTACE.

\section{FURTHER DIRECTION OF ULTRASELECTIVE CTACE}

We believe that the combined use of a small-sized microcatheter and TACE guidance software facilitates transarterial ablation (TAA) for small HCCs including hypovascular tumor portions. ${ }^{8}$ Such tumors are usually less hypervascular, and identification of tumor-feeders, as well as tumor staining, is frequently difficult on DSA. On the other hand, TACE guidance software can easily identify the branches supplying not only the tumor but also the safety margin even in early-stage HCC. A small-sized microcatheter enables selective catheterization into the tiny tumor-feeder and complete blockage of both arterial and portal blood flow in the highly limited area including the tumor. As a result, complete necrosis of the tumor and peritumoral liver parenchyma can be achieved regardless of the tumor vascularity (Fig. 2, 3). We believe that TAA can cure small HCCS and replace surgical resection and radiofrequency ablation in selected patients.

\section{Conflicts of Interest}

The author has no conflicts to disclose.

\section{REFERENCES}

1. Cammá C, Schepis F, Orlando A, Albanese M, Shahied L, Trevisani F, et al. Transarterial chemoembolization for unresectable hepatocellular carcinoma: meta-analysis of randomized controlled trials. Radiology 2002;224:47-54.

2. Brown KT, Do RK, Gonen M, Covery AM, Getrajdman GI, Sofocleous $C T$, et al. Randomized trial of hepatic artery embolization for hepatocellular carcinoma using doxorubicin-eluting microspheres compared with embolization with microspheres alone. J Clin Oncol 2016;34:2046-2053.

3. Kuroda C, Sakurai M, Monden M, Marukawa T, Hosoki T, Tokunaga $K$, et al. Limitation of transcatheter arterial chemoembolization using iodized oil for small hepatocellular carcinoma. A study in resected cases. Cancer 1991;67:81-86.

4. Matsuo N, Uchida H, Nishimine K, Soda S, Oshima M, Nakano H, et al. Segmental transcatheter hepatic artery chemoembolization with iodized oil for hepatocellular carcinoma: antitumor effect and influence on normal tissue. J Vasc Interv Radiol 1993;4:543-549.

5. Miyayama S, Matsui O, Yamashiro M, Ryu Y, Kaito K, Ozaki K, et al. Ultraselective transcatheter arterial chemoembolization with a 2-f tip microcatheter for small hepatocellular carcinomas: relationship between local tumor recurrence and visualization of the portal vein with iodized oil. J Vasc Interv Radiol 2007;18:365-376.

6. Miyayama S, Mitsui T, Zen Y, Sudo Y, Yamashiro M, Okuda M, et al. Histopathological findings after ultraselective transcatheter arterial chemoembolization for hepatocellular carcinoma. Hepatol Res 2009:39:374-381.

7. Miyayama S, Matsui O. Superselective conventional transarterial chemoembolization for hepatocellular carcinoma: rationale, technique, and outcome. J Vasc Interv Radiol 2016;27:1269-1278.

8. Miyayama S, Matsui O. Applying superselective conventional TACE. Endovascular Today 2017;16:52-56.

9. Kim BK, Kim SU, Kim KA, Chung YE, Kim MJ, Park MS, et al. Complete response at first chemoembolization is still the most robust predictor for favorable outcome in hepatocellular carcinoma. J Hepatol 2015;62:1304-1310.

10. Kojiro M, Sugihara S, Kakizoe S, Nakashima O, Kiyomatsu K. Hepatocellular carcinoma with sarcomatous change: a special reference to the relationship with anticancer therapy. Cancer Chemother Pharmacol 1989;23:S4-S8.

11. Zen C, Zen Y, Mitry RR, Corbeil D, Karbanová J, O'Grady J, et al. Mixed phenotype hepatocellular carcinoma after transarterial chemoembolization and liver transplantation. Liver Transpl 2011;17:943954.

12. Wang B, Xu H, Gao ZQ, Ning HF, Sun YQ, Cao GW. Increased expression of vascular endothelial growth factor in hepatocellular carcinoma after transcatheter arterial chemoembolization. Acta Radiol 2008:49:523-529.

13. Miyayama S, Yamashiro M, Sugimori N, Ikeda R, Okimura K, Sakuragawa N. Outcomes of patients with hepatocellular carcinoma 
treated with conventional transarterial chemoembolization using guidance software. J Vasc Interv Radiol 2019;30:10-18.

14. Kim HC, Chung JW, Lee W, Jae HJ, Park JH. Recognizing extrahepatic collateral vessels that supply hepatocellular carcinoma to avoid complications of transcatheter arterial chemoembolization. Radiographics 2005;25 Suppl 1:S25-S39.

15. Miyayama S, Matsui O, Taki K, Minami T, Ryu Y, Ito C, et al. Extrahepatic blood supply to hepatocellular carcinoma: angiographic demonstration and transcatheter arterial chemoembolization. Cardiovasc Intervent Radiol 2006;29:39-48.

16. Goseki N, Nosaka T, Endo M, Koike M. Nourishment of hepatocellular carcinoma cells through the portal blood flow with and without transcatheter arterial embolization. Cancer 1995;76:736-742.

17. Miyayama S, Matsui O, Zen Y, Yamashiro M, Hattori Y, Orito N, et al. Portal blood supply to locally progressed hepatocellular carcinoma after transcatheter arterial chemoembolization: observation on CT during arterial portography. Hepatol Res 2011;41:853-866.

18. Hiraoka A, Kumada T, Kudo M, Hirooka M, Koizumi Y, Hiasa Y, et al. Hepatic function during repeated TACE procedures and prognosis after introducing sorafenib in patients with unresectable hepatocelIular carcinoma: multicenter analysis. Dig Dis 2017;35:602-610.

19. Matsui O, Kadoya M, Kameyama T, Yoshikawa J, Takashima T, Nakanuma $Y$, et al. Benign and malignant nodules in cirrhotic livers: distinction based on blood supply. Radiology 1991;178:493-497.

20. Ekelund L, Lin G, Jeppsson B. Blood supply of experimental liver tumors after intraarterial embolization with gelfoam powder and absolute ethanol. Cardiovasc Intervent Radiol 1984;7:234-249.

21. Ekataksin W. The isolated artery: an intrahepatic arterial pathway that can bypass the lobular parenchyma in mammalian livers. Hepatology 2000;31:269-279.

22. Yoshida K, Matsui O, Miyayma S, Ibukuro K, Yoneda N, Inoue D, et al. Isolated arteries originating from the intrahepatic arteries: anatomy, function, and importance in intervention. J Vasc Interv Radiol 2018;29:531-537.e1.

23. Terayama N, Matsui O, Gabata T, Kobayashi S, Sanada J, Ueda K, et al. Accumulation of iodized oil within the nonneoplastic liver adjacent to hepatocellular carcinoma via the drainage routes of the tumor after transcatheter arterial embolization. Cardiovasc Intervent Radiol 2001;24:383-387.

24. Miyayama S, Yamashiro M, Okuda M, Aburano H, Shigenari N, Morinaga $\mathrm{K}$, et al. Anastomosis between the hepatic artery and the extrahepatic collateral or between extrahepatic collaterals: observation on angiography. J Med Imaging Radiat Oncol 2009;53:271-282.

25. Miyayama S, Matsui O, Yamashiro M, Ryu Y, Takata H, Takeda T, et al. lodized oil accumulation in the hypovascular tumor portion of early-stage hepatocellular carcinoma after ultraselective transcatheter arterial chemoembolization. Hepatol Int 2007;1:451-459.

26. Llovet JM, Di Bisceglie AM, Bruix J, Kramer BS, Lencioni R, Zhu AX, et al. Design and endpoints of clinical trials in hepatocellular carcinoma. J Natl Cancer Inst 2008;100:698-711.

27. Yamakado K, Miyayama S, Hirota S, Mizunuma K, Nakamura K, Inaba $Y$, et al. Hepatic arterial embolization for unresectable hepatocellular carcinomas: do technical factors affect prognosis? Jpn J Radiol 2012;30:560-566.

28. Yamakado K, Miyayama S, Hirota S, Mizunuma K, Nakamura K, Inaba $Y$, et al. Subgrouping of intermediate-stage (BCLC stage B) hepatocellular carcinoma based on tumor number and size and Child-Pugh grade correlated with prognosis after transarterial chemoembolization. Jpn J Radiol 2014;32:260-265.

29. Yamakado K, Miyayama S, Hirota S, Mizunuma K, Nakamura K, Inaba $Y$, et al. Prognosis of patients with intermediate-stage hepatocellular carcinomas based on the Child-Pugh score: subclassifying the intermediate stage (Barcelona Clinic Liver Cancer Stage B). Jpn J Radiol 2014;32:644-649.

30. Llovet JM, Real MI, Montaña X, Planas R, Coll S, Aponte J, et al. Arterial embolisation or chemoembolisation versus symptomatic treatment in patients with unresectable hepatocellular carcinoma: a randomised controlled trial. Lancet 2002;359:1734-1739.

31. Miyayama S, Yamashiro M, Okuda M, Yoshie Y, Sugimori N, Igarashi $S$, et al. Chemoembolization for the treatment of large hepatocellular carcinoma. J Vasc Interv Radiol 2010;21:1226-1234.

32. de Baere T, Arai Y, Lencioni R, Geschwind JF, Rilling W, Salem R, et al. Treatment of liver tumors with Lipiodol TACE: technical recommendations from experts opinion. Cardiovasc Intervent Radiol 2016;39:334-343.

33. Demachi H, Matsui O, Abo H, Tatsu H. Simulation model based on non-newtonian fluid mechanics applied to the evaluation of the embolic effect of emulsions of iodized oil and anticancer drug. Cardiovasc Intervent Radiol 2000;23:285-290.

34. de Baere T, Zhang X, Aubert B, Harry G, Lagrange C, Ropers J, et al. Quantification of tumor uptake of iodized oils and emulsions of iodized oils: experimental study. Radiology 1996;201:731-735.

35. Raoul JL, Heresbach D, Bretagne JF, Ferrer DB, Duvauferrier R, Bourguet $\mathrm{P}$, et al. Chemoembolization of hepatocellular carcinomas. A study of the biodistribution and pharmacokinetics of doxorubicin. Cancer 1992;70:585-590.

36. Irie T, Kuramochi M, Takahashi N. Diameter of main tumor feeding artery of a hepatocellular carcinoma: measurement at the entry site into the nodule. Hepatol Res 2016;46:E100-E104.

37. Miyayama S, Yamashiro M, Hattori Y, Orito N, Matsui $K$, Tsuji $K$, et al. Angiographic evaluation of feeding arteries of hepatocellular carcinoma in the caudate lobe of the liver. Cardiovasc Intervent Radiol 2011;34:1244-1253.

38. Takeuchi Y, Arai Y, Inaba Y, Ohno K, Maeda T, Itai Y. Extrahepatic arterial supply to the liver: observation with a unified CT and angiography system during temporary balloon occlusion of the proper 
hepatic artery. Radiology 1998;209:121-128.

39. Sasaki A, Kai S, Iwashita Y, Hirano S, Ohta M, Kitano S. Microsatellite distribution and indication for locoregional therapy in small hepatocellular carcinoma. Cancer 2005;103:299-306.

40. Ueda K, Matsui O, Kawamori Y, Nakanuma Y, Kadoya M, Yoshikawa J, et al. Hypervascular hepatocellular carcinoma: evaluation of hemodynamics with dynamic CT during hepatic arteriography. Radiology 1998;206:161-166.

41. Sakon M, Nagano H, Nakamori S, Dono K, Umeshita K, Murakami $T$, et al. Intrahepatic recurrences of hepatocellular carcinoma after hepatectomy: analysis based on tumor hemodynamics. Arch Surg 2002;137:94-99.

42. Miyayama S, Yamashiro M, Hashimoto M, Hashimoto N, Ikuno M, Okumura $\mathrm{K}$, et al. Comparison of local control in transcatheter arterial chemoembolization of hepatocellular carcinoma $\leq 6 \mathrm{~cm}$ with or without intraprocedural monitoring of the embolized area using cone-beam computed tomography. Cardiovasc Intervent Radiol 2014;37:388-395.

43. Miyayama S, Yamashiro M, Hattori Y, Orito N, Matsui K, Tsuji K, et al. Efficacy of cone-beam computed tomography during transcath- eter arterial chemoembolization for hepatocellular carcinoma. Jpn J Radiol 2011;29:371-377.

44. Iwazawa J, Ohue S, Hashimoto N, Muramoto O, Mitani T. Survival after C-arm CT-assisted chemoembolization of unresectable hepatocellular carcinoma. Eur J Radiol 2012;81:3985-3992.

45. Miyayama S, Yamashiro M, Hashimoto M, Hashimoto N, Ikuno M, Okumura $\mathrm{K}$, et al. Identification of small hepatocellular carcinoma and tumor-feeding branches with cone-beam CT guidance technology during transcatheter arterial chemoembolization. J Vasc Interv Radiol 2013;24:501-508.

46. Miyayama S, Yamashiro M, Ikuno M, Okumura K, Yoshida M. Ultraselective transcatheter arterial chemoembolization for small hepatocellular carcinoma guided by automated tumor-feeders detection software: technical success and short-term tumor response. Abdom Imaging 2014;39:645-656.

47. Miyayama S, Yamashiro M, Nagai K, Yokka A, Yoshida M, Sakuragawa N. Performance of novel virtual parenchymal perfusion software visualizing embolized areas of transcatheter arterial chemoembolization for hepatocellular carcinoma. Hepatol Res 2017;47:446-454. 